\title{
Genetic effects of static magnetic fields. Body size increase and lethal mutations induced in populations of Drosophila melanogaster after chronic exposure
}

\author{
G Giorgi ${ }^{1 *}$, D Guerra ${ }^{1}$, C Pezzoli ${ }^{1}$, \\ S Cavicchi ${ }^{1}, \mathrm{~F}_{\text {Bersani }}{ }^{2}$ \\ 1 Department of Evolutionary and Experimental Biology, Bologna; \\ ${ }^{2}$ Department of Physics, University of Bologna, 40126 Bologna, Italy
}

(Received 9 August 1991; accepted 5 June 1992)

\begin{abstract}
Summary - The effect of static magnetic fields on body size of Drosophila melanogaster was analyzed on 3 laboratory stocks reared under chronic exposure to a magnetic field 10-12-fold greater than the earth's. A significant increase in body size was observed which persisted even when the flies were returned to control environmental conditions after a few generations of exposure. The genetic basis of the differences observed between treated and control lines was assessed analyzing 2 fitness components and 4 dimensional characters. The increase in body size was mainly associated with cell number, suggesting that the magnetic field effect on size depends on genes which control cell proliferation. The evolution of the fitness components during the generations of exposure gives some evidence of the underlying genetic mechanisms involved. Lines made isogenic for the 3 major chromosomes were tested to establish whether the size response obtained was dependent on the genetic variability or not. These lines behaved in a similar fashion to outbred lines, suggesting that the response in size depends on an increased mutation rate. A mutagenic test confirmed that one generation of exposure induces X-linked lethal mutations. These events could reflect the fact that the magnetic field acts as a physical mutagenic agent at some stage during development.
\end{abstract}

Drosophila melanogaster / magnetic field / lethal mutation / body size / cell proliferation

Résumé - Effet génétique des champs magnétiques statiques : augmentation de la taille corporelle et mutations létales induites dans des populations de Drosophila melanogaster après exposition chronique. L'effet des champs magnétiques statiques

* Correspondence and reprints: G Giorgi, Dipartimento di Biologia Evoluzionistica Sperimentale, via Belmeloro 8, 40126 Bologna, Italy. 
chez Drosophila melanogaster a été analysé dans 3 souches de laboratoire chroniquement soumises à des valeurs du champ magnétique 10-12 fois plus élevées que le champ magnétique terrestre. Après quelques générations on observe une augmentation significative de la taille corporelle, qui se maintient lorsque les souches sont replacées dans les conditions standard. Pour établir la base génétique des différences observées entre les lignées traitées et non traitées, 2 composantes de la valeur adaptative et la longueur des 4 nervures longitudinales de l'aile ont été analysées sur une des 3 souches. Le croisement entre la lignée traitée et la lignée témoin de cette souche montre que la différenciation génétique entre les 2 lignées est très forte. L'augmentation de la taille de l'aile est surtout associée au nombre des cellules. Cela suggère que l'effet du champ magnétique est dépendant des gènes qui contrôlent la prolifération cellulaire. L'évolution des composantes de la fitness pendant l'exposition donne un aperçu des mécanismes génétiques impliqués. Au cours des premières générations, une réduction marquée de la fécondité et un affaiblissement du développement de l'aeuf chez l'adulte sont observés dans toutes les lignées étudiées. Pour établir si la réponse obtenue dépend de la variabilité génétique des souches considérées, nous avons testé des lignées isogéniques pour les 3 chromosomes majeurs. Ces dernières répondent de la même façon que les lignées d'origine, ce qui indique que l'augmentation de la taille dépend d'une fréquence de mutation plus élevée. Un essai de mutagenèse confirme que l'exposition à des champs magnétiques 10 à 12 fois plus élevés que la normale conduit à des taux de mutations létales liées au sexe 10 fois plus élevés que chez les témoins.

Drosophila melanogaster / champ magnétique / taille corporelle / mutation létale / prolifération cellulaire

\section{INTRODUCTION}

Studies on the effect of magnetic fields on living organisms are interesting from both theoretical and practical points of view.

The geomagnetic field is a natural environmental factor variable in space and time so that all living organisms are affected differently. This is due to the fact that the intensity of the geomagnetic field follows a geographic slope from the magnetic equator to the geomagnetic poles, approximately from 0.25 to 0.70 Gauss, and the dipole field intensity has decayed by $7 \%$ in the last 100 years (Bloxham and Gubbins, 1985).

A fascinating theory for a significant influence of geomagnetism upon terrestrial life is the correlation between the time of extinction of certain living species and the occurrence of geomagnetic polarity reversals which may trigger the loss of magnetic shielding during the possible zero dipole shield condition (Watkins and Goodell, 1967).

The practical interest in the effect of static magnetic fields involves many topics in physiology and medicine, including nuclear magnetic resonance (NMR) imaging, magnetic separation of biological materials and orientation of cell fragments in suspension.

Over the last 20 years the biological effects of magnetic fields studied in different laboratory animals have varied widely in relation to the organism and the experimental protocol, providing contrasting results. 
Mutagenic effects have been investigated. Exposure of adults for a short period to high magnetic fields failed to reveal significant differences between exposed and sham-exposed groups of Drosophila (Mittler, 1971; Kale and Baum, 1979, 1982 ; Mulay and Mulay, 1961, 1964), Salmonella (Anderstam et al, 1983; Juutilainen and Liimatainen, 1986) or mice (Mahlum et al, 1979).

Morphogenetic anomalies and altered development times were apparent when Drosophila melanogaster pupae were subjected to magnetic fields (Levengood, 1966, 1967) and when Drosophila melanogaster flies remained in a gradient of low magnetic field until the appearance of the first offspring (Tegenkamp, 1969).

Physiological and developmental effects have also been investigated. The regulation of growth and differentiation of Drosophila (Goodman, 1976; Goodman et al, 1979), Escherichia coli (Ramon et al, 1981) and mammalian cells (Malinin et al, 1976; Frazier et al, 1979) are affected by strong magnetic fields.

Little information is available on permanent genetic effects. A reduction in spawn rate and gestation period was found when guppies (Lebistes reticulatus) were chronically exposed to a homogeneous magnetic field, but the effect is concealed when the fish are removed from the magnetic field (Brewer, 1979).

Delays in the mitotic cycle of the myxomycetes, Physarum polycephalum, were noted after continuous exposure to electromagnetic fields. This effect also disappears, though not immediately, when the culture is removed from the field simulator (Marron et al, 1975).

More recent molecular studies have demonstrated further effects. In the presence of varying magnetic fields, the transcription autoradiogram of dipteran salivary gland cells markedly increased the specific activity of messenger RNA (Goodman et al, 1983, 1987; Weisbrot et al, 1988) and enhanced DNA synthesis in human fibroblasts was also reported following exposure (Liboff et al, 1984). All these findings suggest a raised mitotic rate which could lead to an increase in size.

The relationship between environmental stresses and genetic reorganization has been examined in a number of instances, but the ways in which organisms perceive the stress and respond are unknown. Changes in plant DNA, environmentally induced, have already been shown in certain flax varieties. In a single generation of stress, there was an alteration which was heritable and could not be reversed by restoration of the original conditions (Durrant, 1971; Cullis, 1986, 1990).

A range of phenomena can be responsible for these rapid genomic changes, including the activity of transposable elements, amplification and deletion events. Some experimental results, controversially, have been interpreted as evidence for a form of directed mutation (Cairns et al, 1988), but further experimental data will be required to study the possibility of environmentally induced mutation in the genome.

This study aimed to approach this topic by means of formal genetic analysis using Drosophila melanogaster, an organism suitable for this kind of study. Here we determine the effect of a chronic static magnetic field 10-12-fold greater than the earth's on body size and relate the effect to an increased mutational rate.

As differences in body size seem related to variations in cell size and number (Robertson, 1959a,b; Cavicchi et al, 1985), we also investigated the factors responsible for changes in body size by assessing variations in cell size and number in the wing surface of the populations studied. 


\section{MATERIALS AND METHODS}

\section{Exposure system}

The exposure system consisted of a function generator and a power amplifier (50 $\mathrm{Hz}$ ) (generator stabilized by a continuous current) connected to several coils for simultaneous exposure to magnetic field strengths. The coils used for exposure were constructed of aluminium tube (inside diameter $2 r=4.6 \mathrm{~cm}$; length $l=10.3 \mathrm{~cm}$; turns of $0.2 \mathrm{~mm}$ copper wire $\mathrm{No}=3500$ ).

The magnetic flux density or magnetic induction $B$ at the center of the coils was calculated from:

$$
B=\frac{\mu_{0} N I}{2 \sqrt{\left[r^{2}+\left(l^{2} / 4\right)\right]}}
$$

where $I=$ electric current (A) and $\mu_{0}=4 \pi 10^{-3} \mathrm{H} / \mathrm{m}$ (Henry per meter) is the magnetic permeability of free space expressed in Gauss.

An active uniform horizontal magnetic field was calculated from the center of the coils of 7.0 Gauss, to the external section of 4.0 Gauss. This intensity (10-12-fold greater than the geomagnetic field) was measured by a gaussmeter.

The coils were custom-built to house 2 vials (outsite diameter $2 r=3.2 \mathrm{~cm}$ ) in the center of the horizontal beam of magnetic strength. The vials were inserted one against the other so as to ensure that all individuals were confined to the most uniform point of maximum magnetic field intensity throughout their development. No rise in temperature was noted within the coils which were stored in thermostated chambers at $25^{\circ} \mathrm{C}$ alongside control lines where only the local geomagnetic field was measured.

\section{Stocks}

Three different stocks of Drosophila melanogaster were used: 1) Oregon-R (O) maintained for over $20 \mathrm{yr}$ in our laboratory under standard breeding conditions; and 2 wild stocks collected in 2 different Italian localities; 2) near Bologna (C) and 3 ) near Rieti (R) and kept for $5 \mathrm{yr}$ and $3 \mathrm{yr}$ respectively in the laboratory under controlled conditions of temperature $\left(25^{\circ} \mathrm{C}\right)$ and humidity $(70 \%)$. The 3 stocks showed a good degree of additive genetic variability $\left(h^{2}\right)$ for wing length $(0.29$ in $\mathrm{O}$ strain; 0.33 in $\mathrm{C}$ strain; 0.34 in $\mathrm{R}$ strain) calculated by the sib analysis method and as parent-offspring regression (Falconer, 1970).

\section{The experiment of exposure}

Thirty random pairs from each of the 3 stocks wcre left to lay eggs overnight in 6 different vials. Twelve samples of 80 eggs each were collected the following morning: 6 made up the control line subjected to the effect of the geomagnetic field alone while the other 6 were exposed to the induced magnetic field.

Control lines were maintained within coils the same size as those adopted for the experiment and fed by the same feeder but with an equal number of spiral loops so as not to generate any magnetic ficld despite the flow of current. 
On reaching sexual maturity, adults were counted and measured and 30 pairs were randomly left to lay within the coils in a new set of vials; breeding took place at a constant temperature of $25^{\circ} \mathrm{C}$.

A fixed number of eggs per vial avoided competition for the medium which may affect larval survival and body size.

This experimental protocol was started with stock $\mathrm{C}$ and continued for 59 generations. The same procedure was repeated to create 2 further treatment lines $\left(\mathrm{C}_{2}\right.$ and $\left.\mathrm{C}_{3}\right)$, maintained for only 4 generations. The experiment was further repeated with the other 2 stocks, $\mathrm{O}$ and $\mathrm{R}$, both of which were followed for 43 generations.

Many releases were set up from all the treated lines at different experimental times for a varying number of generations. In particular, $\mathrm{C}$ line releases were set up at the $3 \mathrm{rd}, 5 \mathrm{th}, 10 \mathrm{th}$ and $27 \mathrm{th}$ generation while releases from $\mathrm{C}_{3}$ were only made at the 4 th generation; 2 release lines were made at the 5 th generation for the $\mathrm{O}$ and $\mathrm{R}$ populations.

Wing length was used to determine changes in body size. The length of $\mathrm{L}_{4}$ vein was taken as wing length and measured under a microscope at magnification $\times 25.2$, with an ocular micrometer of 100 divisions. In all tested lines (treated, control and released) for some generations (from 1 to 10, from 16 to 27, the 34 th and the 59th) the wings were dissected and mounted on slides and a variable number of right female wings of each experimental line were measured (see results).

To check whether variations in wing size were reflected in other body dimensions, thorax and head size were measured at the 34 th generation for stock $\mathrm{C}$ (including 2 release lines) and at the 18 th generation for stocks $\mathrm{R}$ and Oregon (together with 1 release line).

\section{Genetic test}

For stock $\mathrm{C}$ alone, a scheme of reciprocal crosses between treated and control lines was made after 9 generations to assess possible genetic differences. Parents and $F_{1} s$ were raised simultaneously with $\mathrm{F}_{2} \mathrm{~s}$, by crossing parental strains twice in successive gencrations. Ten single pairs for 3 replicates per reciprocal cross were left to lay and the development time and number of offspring recorded. At each generation, the right wings of 6 females of each progeny were dissected, mounted on slides and measured.

Variations in cell size and number were evaluated considering a wing surface delimited by the triangle whose sides are represented by the $\mathrm{L}_{2}$ and $\mathrm{L}_{4}$ veins and the distance between them at the margin of the wing. The triangle area was computed by Erone's formula:

$$
S=\sqrt{[p(p-a)(p-b)(p-c)]}
$$

where $p$ is half the perimeter and $a, b$ and $c$ are the lengths of the sides of the triangle.

Cell area was estimated under a microscope at a total magnification $\times 375$ by counting the number of bristles/cells present on a dorsal surface of $84.05 \times$ $10^{-4} \mathrm{~mm}^{2}$ limited by a reticle placed in the eyepiece.

In this work, the reticle was placed at first between $\mathrm{L}_{2}$ and $\mathrm{L}_{3}$ veins, then between $\mathrm{L}_{3}$ and $\mathrm{L}_{4}$ veins; the counts were averaged. Previous studies show that the cells 
are regularly arranged on the wing surface and counts in different regions are quite well correlated so that variations in one wing region reflect variations in the whole wing (Robertson, 1959a; Delcour and Lints, 1966).

The average cell area was estimated by dividing the area of the reticle by the number of cells counted. Cell number was obtained by dividing wing size by cell area; the measurements were converted to natural logarithms. In this form, wing area is the sum of cell area and number.

\section{Isogenic lines}

In order to establish whether the effect of magnetic field depends on pre-existing genetic variability in a given population or not, a short time test on isogenic lines was made. These lines were made isogenic for the 3 major chromosomes as there is no evidence in the literature of 4 th chromosomes genes involved in size variations.

Virgin females of the natural stock $\mathrm{C}$ were mated with males of a multiple balanced stock: Binsc; $\mathrm{SM}_{5} / \mathrm{bw}^{v 1} ; \mathrm{TM}_{3} / \mathrm{Sb}$ (Lindsley and Grell, 1968). Female heterozygotes Binsc $/^{+} ; \mathrm{SM}_{5} /^{+} ; \mathrm{TM}_{3} /^{+}$were backcrossed in single pairs with males from the balanced stock to obtain replications of the same chromosomes in males and females. Isogenic males and females from all 3 chromosomes were obtained in the subsequent generation.

\section{Sex-linked recessive lethal test}

Two vials with 30 random pairs from the 2 wild-type stocks (C and $R$ ) were kept within the coils generating the magnetic field. The emerging flies were removed and each male progeny was mated with a virgin female from the $\mathrm{FM}_{6} / \mathrm{FM}_{7}$ balancer stock (Lindsley and Grell, 1968).

Each $F_{1}$ progeny was examined and pairs mated in vials. The $F_{2}$ progeny which hatched in these vials were examined for the presence or absence of males. Complete absence of such males indicated a lethal mutation. All suspect lethals were confirmed by testing for one more generation. The experiment was repeated several times and a total of $4197 \mathrm{X}$-chromosomes were analyzed.

\section{RESULTS}

\section{Wing length}

Wing length of control and treated stocks during different generations is given in table I and variation coefficients in table II. Only replicate (a) for the C stock is shown.

The effect of chronic magnetic field is also given as percentage deviation from controls in figures 1 and $2\left(\mathrm{a}=\right.$ line $\mathrm{C} ; \mathrm{b}=$ lines $\mathrm{C}_{2}$ and $\mathrm{C}_{3} ; \mathrm{c}=$ line $\mathrm{O} ; \mathrm{d}=$ line R).

The results show that the magnetic field always increases wing size. A sharp significant response to magnetic field is observed in the first generations, becoming slower from the 20th generation. Responses were similar for all stocks and stabilized at around $3 \%$ after many generations. 
Table I. Wing length $( \pm \mathrm{SE})$ in the control and treated stocks for different generations.

\begin{tabular}{|c|c|c|c|c|c|c|}
\hline \multirow{2}{*}{$\begin{array}{l}\text { Gene- } \\
\text { ration }\end{array}$} & \multicolumn{2}{|c|}{$C$ stock } & \multicolumn{2}{|c|}{ O stock } & \multicolumn{2}{|c|}{$R$ stock } \\
\hline & Control & Treated & Control & Treated & Control & Treated \\
\hline 1 & 22 & 23 & 0.16 & 5 & 11 & 0 \\
\hline 2 & & & 0.14 & & & \\
\hline 3 & 17 & 54.90 & 0.10 & 0.11 & $=0.09$ & 0.09 \\
\hline 4 & 0.15 & 55. & 0.10 & 0.10 & $52.00 \pm 0.11$ & $52.60 \pm 0.09$ \\
\hline 5 & $53.83 \pm 0.13$ & $55.11=$ & $52.66 \pm 0.08$ & 53.38 & $52.52 \pm 0.10$ & $=0.10$ \\
\hline 6 & $53.74 \pm 0.11$ & $54.75 \pm 0.09$ & $52.90 \pm 0.10$ & 53.67 & $52.74 \pm 0.09$ & 53.86 \\
\hline 8 & $52.73 \pm 0.12$ & $54.27 \pm 0.16$ & $52.94 \pm 0.08$ & $53.98 \pm 0.09$ & $.52 .64 \pm 0.10$ & $53.76 \pm 0.10$ \\
\hline 9 & $53.70 \pm 0.16$ & $55.20 \pm 0.15$ & $52.75 \pm 0.10$ & $54.26 \pm 0.08$ & $52.45 \pm 0.11$ & $53.98 \pm 0.10$ \\
\hline 10 & $54.10 \pm 0.17$ & $55.30 \pm 0.18$ & $52.27 \pm 0.10$ & $53.42 \pm 0.09$ & $51.45 \pm 0.09$ & $52.68 \pm 0.08$ \\
\hline 16 & $53.41 \pm 0.09$ & $54.92 \pm 0.10$ & $52.91 \pm 0.08$ & $54.25 \pm 0.08$ & $51.82 \pm 0.11$ & $53.54 \pm 0.12$ \\
\hline 18 & $53.29 \pm 0.13$ & $55.27 \pm 0.11$ & $53.59 \pm 0.10$ & $54.77 \pm 0.09$ & $53.65 \pm 0.15$ & $55.37 \pm 0.13$ \\
\hline 43 & $53.14 \pm 0.12$ & $55.70 \pm 0.11$ & $50.59 \pm 0.14$ & $52.60 \pm 0.11$ & $51.11 \pm 0.11$ & $52.65 \pm 0.13$ \\
\hline
\end{tabular}

A variable number of flies were measured each generation: only 24 flies in control and treated lines of the $\mathrm{C}$ stock at the lst generation, and a number ranging from 30 to 119 flies in the remaining stocks and generations. Measures are given in micrometric units. One unit corresponds to $3.8 \times 10^{-2} \mathrm{~mm}$. Only 1 replicate (a) of the $\mathrm{C}$ stock is reported.

Table II. Coefficients of variation of wing length in the control and treated stocks for different generations. Only one replicate (a) of the $\mathrm{C}$ stock is reported.

\begin{tabular}{|c|c|c|c|c|c|c|}
\hline \multirow{2}{*}{$\begin{array}{l}\text { Gene- } \\
\text { ration }\end{array}$} & \multicolumn{2}{|c|}{$C$ stock } & \multicolumn{2}{|c|}{ O stock } & \multicolumn{2}{|c|}{$R$ stock } \\
\hline & Control & Treated & Control & Treated & Control & Treated \\
\hline 1 & 1.97 & 2.05 & 2.58 & 2.20 & 2.14 & 2.25 \\
\hline 2 & 2.16 & 2.01 & 2.55 & 2.54 & 1.78 & 1.94 \\
\hline 3 & 2.32 & 2.14 & 1.90 & 1.91 & 1.64 & 1.50 \\
\hline 4 & 1.59 & 1.80 & 1.89 & 1.61 & 2.11 & 1.68 \\
\hline 5 & 1.86 & 1.62 & 1.30 & 1.00 & 1.63 & 1.60 \\
\hline 6 & 1.12 & 0.90 & 1.70 & 1.31 & 1.60 & 1.54 \\
\hline 8 & 1.97 & 1.61 & 1.49 & 1.27 & 1.65 & 1.47 \\
\hline 9 & 1.63 & 1.49 & 1.75 & 1.27 & 1.85 & 1.43 \\
\hline 10 & 1.72 & 1.78 & 1.72 & 1.37 & 1.73 & 1.49 \\
\hline 16 & 1.93 & 1.48 & 1.39 & 1.38 & 1.56 & 2.05 \\
\hline 18 & 1.99 & 1.42 & 1.31 & 1.07 & 1.95 & 1.59 \\
\hline 43 & 1.58 & 1.48 & 2.38 & 1.47 & 1.83 & 1.91 \\
\hline
\end{tabular}

Table III lists the rate of increase in wing size for the lines tested. Results are expressed in terms of regression ( $\mathrm{b} \pm \mathrm{SE}$ ) of the standardized response over the first 10 generations. Table III also gives the rate of increase for line $\mathrm{C}$ following artificial selection in the plus direction with a selection intensity of $20 \%$. No significant heterogeneity in slope was observed between the 4 regression lines. Hence, the 

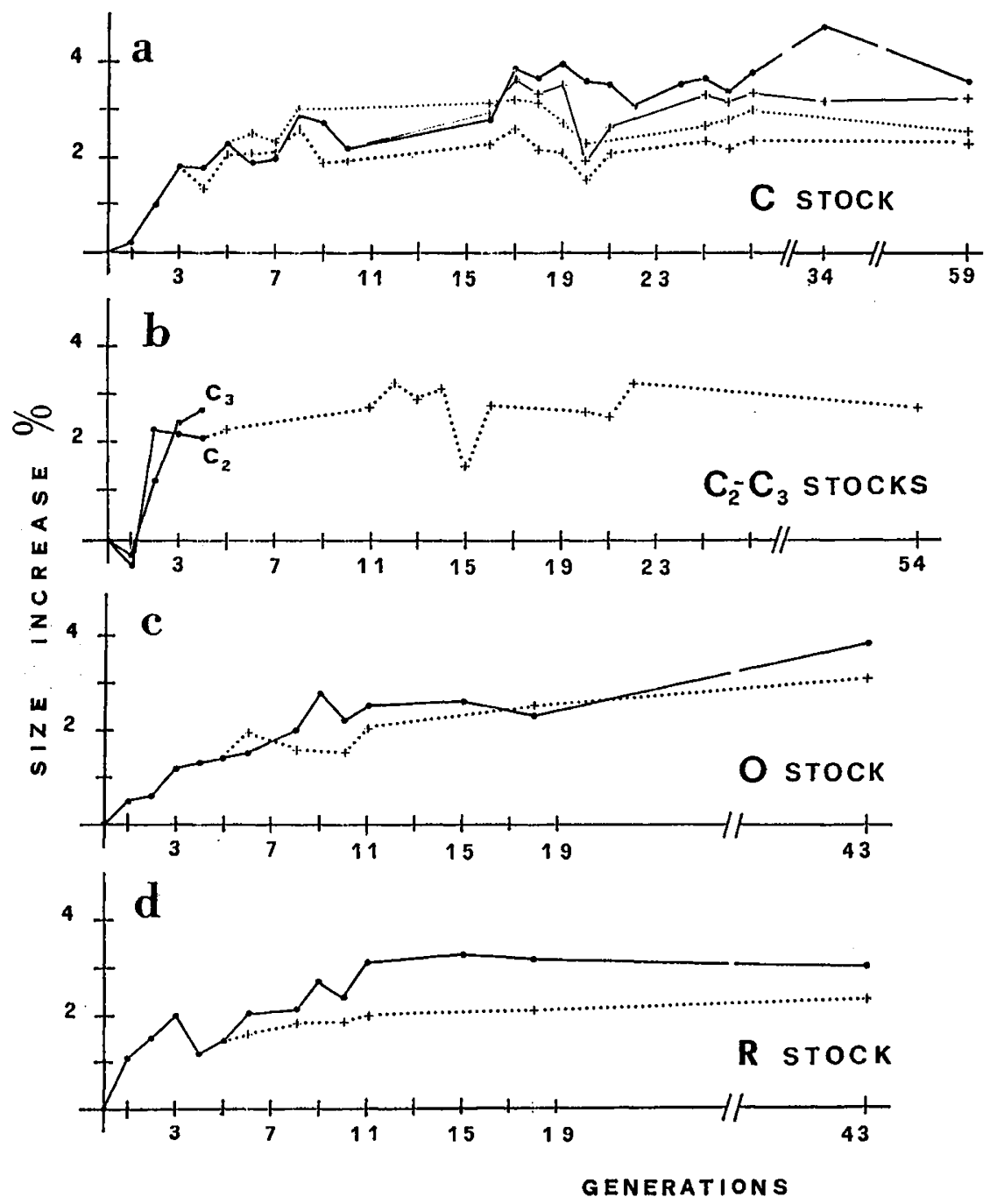

Fig 1. Percent wing size increase during treatment generations in different stocks. Dotted lines refer to stocks.

treatment lines presented a rate of increase similar to that obtained following artificial selection.

Figure 1 also shows the results of the release lines (dashed lines) at the 5 th generation in the $\mathrm{R}$ and $\mathrm{O}$ lines and at generations 3,5 and 10 in the $\mathrm{C}$ line, further replicated in the $\mathrm{C}_{2}$ line only at the 4 th generation. The results show that the magnetic field effect persists even after treatment is discontinued irrespective of the number of treated generations. 


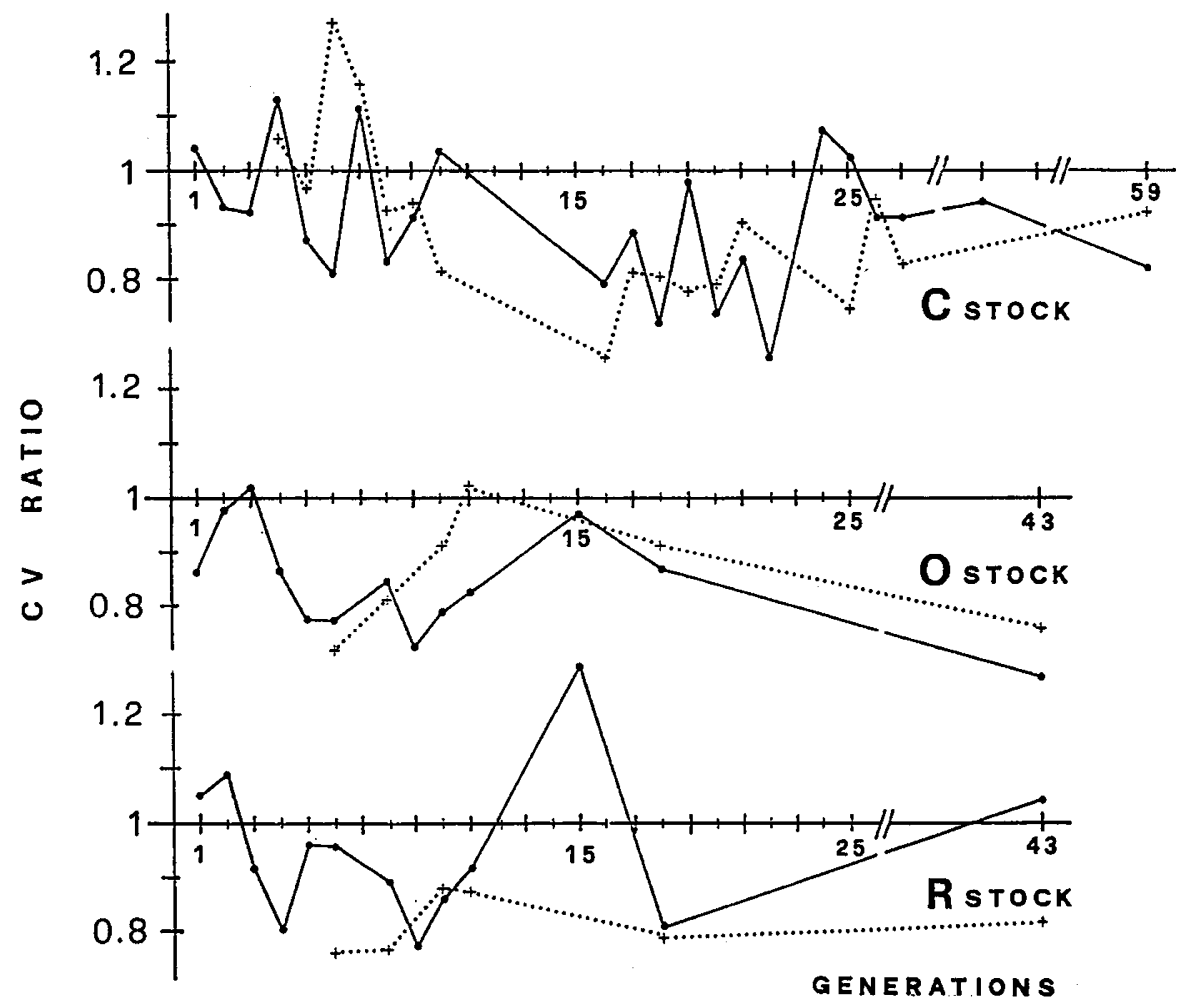

Fig 2. Ratio between the coefficients of variation (CV) of treated and control stocks (straight lines) and between released and control stocks (dotted lines) for different generations.

Phenotypic variability in all the studied lines was reported as coefficients of variation. The results are presented in table II and in figure 2 as the ratio between values obtained in the treated lines and values in controls. Only replicate (a) of the $\mathrm{C}$ stock is shown. The treated lines are characterized by a relatively lower variability than the controls, which is maintained in the released lines. This effect is present from the first generations.

\section{Other body size traits}

The whole organism was measured for size response at the 34 th generation for stock $\mathrm{C}$ and at the 18th generation for $\mathrm{O}$ and $\mathrm{R}$.

Table IV summarizes the differences between the treated and control lines in thorax length and width, head width and wing length. There was a significant difference in whole body size although an allometric response was present as a differential response by the different characters. 
Table III. (A) Rate of increase in wing size during 10 generations of artificial selection in the $\mathrm{C}$ stock (Cs) and rate of increase during 10 generations of magnetic field treatment in 3 lines of different stocks ( $\mathrm{C}, \mathrm{R}$ and $\mathrm{O})$. The rate is expressed as regression coefficient $(b \pm \mathrm{SE})$ of the standardized response over the 10 generations. (B) Comparison between slopes is given by ANOVA.

\begin{tabular}{lll}
\hline (A) & & \multicolumn{1}{c}{$b \pm S E$} \\
\hline & Cs & $0.185 \pm 0.036$ \\
& $\mathrm{C}$ & $0.161 \pm 0.029$ \\
$\mathrm{R}$ & $0.130 \pm 0.027$ \\
& $\mathrm{O}$ & $0.168 \pm 0.016$ \\
\hline (B) & $d f$ & Mean squares \\
\hline Deviations pooled & 32 & 0.0773 \\
Between slopes & 3 & $0.0514 \mathrm{NS}$ \\
\hline
\end{tabular}

$\mathrm{NS}=$ not significant.

Table IV. (A) Mean values ( \pm SE) of different body traits in control and treated lines of stocks $\mathrm{C}(\mathrm{Cc}$ and $\mathrm{Ct}), \mathrm{O}(\mathrm{Oc}$ and $\mathrm{Ot}$ ) and $\mathrm{R}(\mathrm{Rc}$ and $\mathrm{Rt}$ ). Measurements were taken at the 34th generation for the $\mathrm{C}$ stock and at the 18th generation for the $\mathrm{R}$ and $\mathrm{O}$ stocks. Measures are given in micrometric units. One unit corresponds to $3.8 \times 10^{-2} \mathrm{~mm}$. (B) Differences between mean values of control and treated lines. Significance is based on the $t$-test.

\begin{tabular}{|c|c|c|c|c|c|c|}
\hline & & & Thorax length & Thorax width & Head size & Wing size \\
\hline \multicolumn{7}{|c|}{ (A) } \\
\hline & Lines & $\mathrm{N}$ & & & & \\
\hline & $\mathrm{Cc}$ & 49 & $24.286 \pm 0.071$ & $19.694 \pm 0.067$ & $21.020 \pm 0.036$ & $53.143 \pm 0.127$ \\
\hline & $\mathrm{Ct}$ & 56 & $25.679 \pm 0.068$ & $20.143 \pm 0.054$ & $21.839 \pm 0.036$ & $55.696 \pm 0.111$ \\
\hline & $\mathrm{Oc}$ & 49 & $24.551 \pm 0.077$ & $19.898 \pm 0.060$ & $21.081 \pm 0.057$ & $53.592 \pm 0.101$ \\
\hline & Ot & 49 & $25.367 \pm 0.069$ & $20.571 \pm 0.071$ & $21.408 \pm 0.070$ & $54.776 \pm 0.084$ \\
\hline & $\mathrm{Rc}$ & 49 & $24.571 \pm 0.071$ & $20.184 \pm 0.081$ & $21.755 \pm 0.069$ & $53.653 \pm 0.161$ \\
\hline & Rt & 49 & $25.531 \pm 0.072$ & $20.980 \pm 0.055$ & $22.653 \pm 0.069$ & $55.367 \pm 0.126$ \\
\hline \multicolumn{7}{|l|}{ (B) } \\
\hline & Comp & $d f$ & & & & \\
\hline & $\mathrm{Ct}-\mathrm{Cc}$ & 103 & $-1.393^{*}$ & $-0.449^{*}$ & $-0.819^{*}$ & $-2.553^{*}$ \\
\hline & Ot-Oc & 96 & $-0.816^{*}$ & $-0.673^{*}$ & $-0.327^{*}$ & $-1.184^{*}$ \\
\hline & Rt-Rc & 96 & $-0.960^{*}$ & $-0.796^{*}$ & $-0.898^{*}$ & $-1.732^{*}$ \\
\hline
\end{tabular}

* Significance at the $1 \%$ level. 


\section{Fitness components}

Fecundity and viability of control and treated lines are given in table $\mathrm{V}$ and as percentages of controls in figure $3 \mathrm{a}$ and $3 \mathrm{~b}$. There is evidence of a marked reduction in egg laying in all the treated lines in the first generations. This decrease disappears from the 5th-6th generation, returning to values similar to controls.

Table V. (A) Mean values ( $\pm \mathrm{SE}$ ) of fecundity in control and treated lines of $\mathrm{C}, \mathrm{O}$ and $\mathrm{R}$ stocks during 7 generations. The significance is based on the $t$-test. (B) Flies/eggs in the control and treated lines of the 3 stocks for different generations. The significance is based on $2 \times 2$ contingency tables. Only one replicate (a) of C stock is reported.

\begin{tabular}{|c|c|c|c|c|c|c|}
\hline \multirow{2}{*}{$\begin{array}{l}\text { Gene- } \\
\text { ration }\end{array}$} & \multicolumn{2}{|c|}{$C$ stock } & \multicolumn{2}{|c|}{ O stock } & \multicolumn{2}{|c|}{$R$ stock } \\
\hline & Control & Treated & Control & Treated & Control & Treated \\
\hline \multicolumn{7}{|l|}{ (A) } \\
\hline 1 & $27.40 \pm 1.99$ & $15.86 \pm 3.17^{*}$ & $15.27 \pm 2.27$ & $9.77 \pm 1.25^{*}$ & $18.46 \pm 2.44$ & $10.03 \pm 1.86^{*}$ \\
\hline 2 & $14.88 \pm 2.30$ & $7.94 \pm 1.19^{*}$ & $19.37 \pm 1.14$ & $14.84 \pm 2.02^{*}$ & $22.16 \pm 1.67$ & $16.29 \pm 2.22^{*}$ \\
\hline 3 & $14.98 \pm 5.09$ & $12.24 \pm 3.63$ & $21.17 \pm 2.76$ & $18.33 \pm 1.54$ & $25.27 \pm 2.91$ & $21.44 \pm 1.09$ \\
\hline 4 & $26.47 \pm 4.10$ & $20.15 \pm 4.56$ & $19.86 \pm 1.78$ & $22.15 \pm 3.84$ & $30.22 \pm 6.27$ & $24.16 \pm 2.44$ \\
\hline 5 & $15.67 \pm 2.99$ & $16.50 \pm 4.23$ & $27.69 \pm 4.04$ & $25.61 \pm 5.98$ & $24.88 \pm 2.40$ & $26.77 \pm 6.76$ \\
\hline 6 & $19.75 \pm 6.29$ & $18.48 \pm 5.89$ & $28.44 \pm 3.33$ & $30.88 \pm 3.17$ & $32.77 \pm 3.66$ & $28.80 \pm 3.58$ \\
\hline$(B)^{7}$ & $26.56 \pm 6.68$ & $24.48 \pm 2.22$ & $24.28 \pm 3.91$ & $21.61 \pm 3.24$ & $26.19 \pm 4.57$ & $25.33 \pm 4.25$ \\
\hline (D) 1 & 0.45 & 0.48 & 0.73 & 0.77 & 0.87 & 0.81 \\
\hline 2 & 0.67 & $0.53^{*}$ & 0.77 & $0.71^{*}$ & 0.80 & $0.71^{*}$ \\
\hline 3 & 0.63 & $0.53^{*}$ & 0.76 & 0.78 & 0.83 & $0.77^{*}$ \\
\hline 4 & 0.56 & $0.47^{*}$ & 0.75 & $0.70^{*}$ & 0.84 & 0.88 \\
\hline 5 & 0.57 & $0.49^{*}$ & 0.74 & 0.76 & 0.81 & 0.81 \\
\hline 6 & 0.61 & 0.56 & 0.78 & 0.75 & 0.89 & $0.81^{*}$ \\
\hline 8 & 0.60 & 0.59 & 0.67 & 0.61 & 0.82 & $0.71^{*}$ \\
\hline 9 & 0.53 & $0.40^{*}$ & 0.77 & $0.64^{*}$ & 0.84 & $0.73^{*}$ \\
\hline 10 & 0.49 & $0.43^{*}$ & 0.64 & $0.56^{*}$ & 0.83 & $0.74^{*}$ \\
\hline 11 & 0.62 & 0.59 & 0.81 & $0.71^{*}$ & 0.83 & $0.75^{*}$ \\
\hline 18 & 0.66 & 0.68 & 0.76 & 0.79 & 0.80 & 0.81 \\
\hline 43 & 0.62 & 0.63 & 0.83 & 0.82 & 0.81 & 0.86 \\
\hline
\end{tabular}

* Significance at the $5 \%$ level.

The differences in the percentage of eggs yielding adult flies (viability) between treated and control lines are given in figure $3 \mathrm{~b}$. Magnetic field reduces the viability of all lines studied compared with controls. The trend is less regular than that of fecundity; however, there are highly significant differences $\left(\chi^{2}\right.$ test based on $2 \times 2$ contingency table at each generation) between flies exposed to the magnetic field and control flies, during almost all the first 11 generations (table $\mathrm{Vb}$ ). The viability of flies exposed resembles controls only after the 17 th generation. 

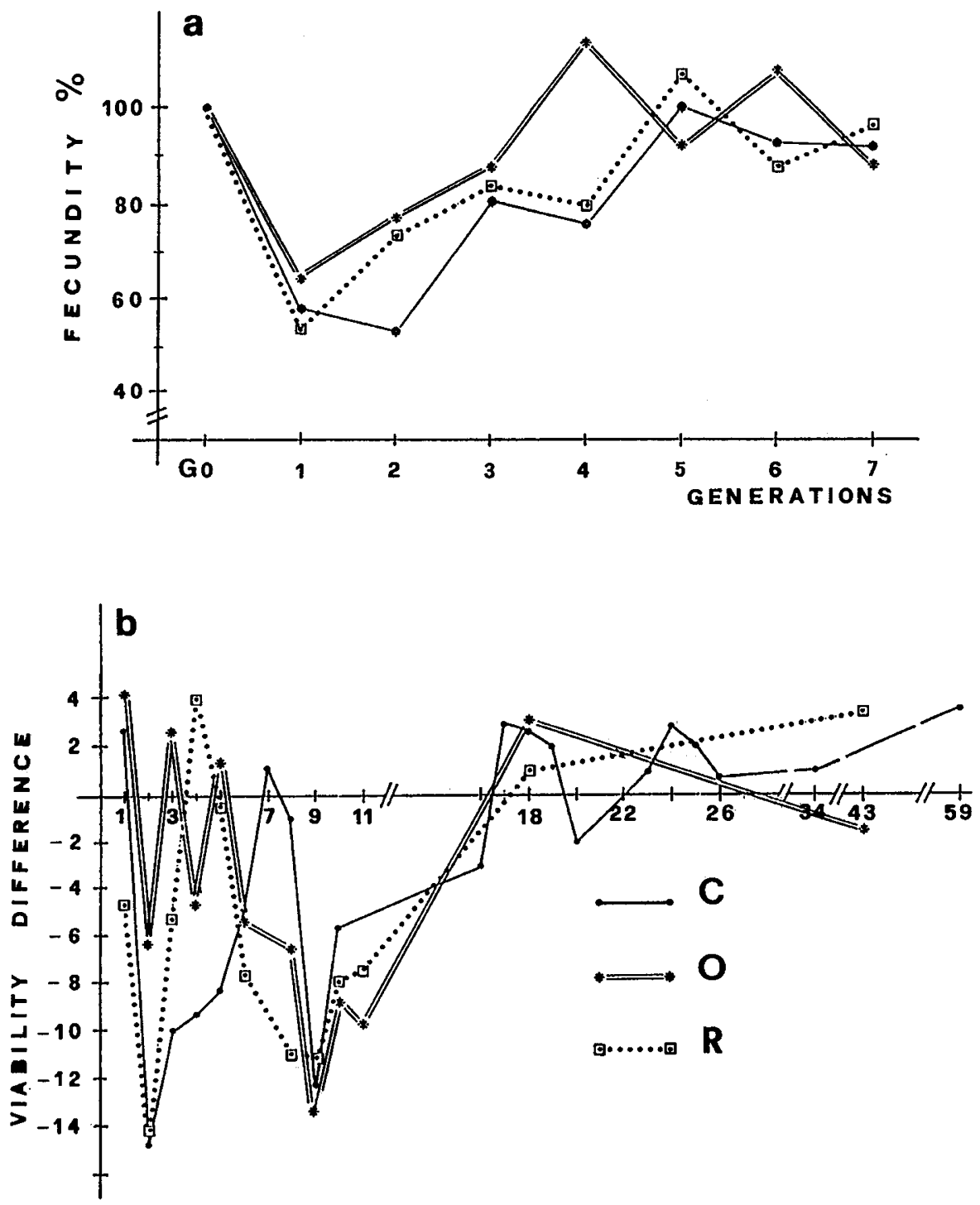

Fig 3. A) Percent eggs laid in the treated stocks relative to the controls during 7 generations. B) Viability (\% flies/eggs) differences between treated and control stocks for different generations. 


\section{Response of isogenic lines}

To establish whether the size response obtained is dependent on pre-existing genetic variability, lines made isogenic for the 3 major chromosomes were bred for 7 generations at the same magnetic field intensity as that used previously.

Table VI shows the wing size response of 2 replicated isogenic lines from the $\mathrm{C}$ stock. The response is similar to that obtained at the same generation in the 3 stocks previously considered.

Table VI. Mean values $\left( \pm \mathrm{SE}\right.$ ) obtained in 2 replicates $\left(\mathrm{R}_{1}\right.$ and $\left.\mathrm{R}_{2}\right)$ of 2 isogenic lines (1-9 and l-16) of the $\mathrm{C}$ stocks. Measurements were taken after 7 treatment generations.

\begin{tabular}{|c|c|c|c|c|}
\hline & \multicolumn{2}{|c|}{$\begin{array}{c}\text { Lines } \\
1-9\end{array}$} & \multicolumn{2}{|c|}{$\begin{array}{c}\text { Lines } \\
1-16\end{array}$} \\
\hline & $R e p R_{1}$ & $\operatorname{Rep} R_{2}$ & $\operatorname{Rep} R_{1}$ & $\operatorname{Rep~} R_{2}$ \\
\hline Control & $58.39 \pm 0.096$ & $57.95 \pm 0.071$ & $58.10 \pm 0.073$ & $58.01 \pm 0.078$ \\
\hline Treated & $59.36 \pm 0.085^{*}$ & $59.11 \pm 0.084^{*}$ & $58.98 \pm 0.075^{*}$ & $59.01 \pm 0.076^{*}$ \\
\hline
\end{tabular}

Rep $=$ replicate; Significance is based on the $t$-test $;{ }^{*}$ Significance at the $1 \%$ level.

\section{Genetic analysis}

The genetic basis of the differences observed between the 2 lines, treated and control, was detected on $\mathrm{C}$ stock at the 9 th generation by crossing treated and untreated flies, after one generation of transfer out of the magnetic field. Wing size and 2 fitness components are taken into account: development time measured as the average number of days required from deposition to emergence of the progeny of 1 female after 1 day's laying, and productivity, measured as the number of emerged flies which combined to the different components: female fecundity, egg viability, male mating ability and fertility.

As regards wing length, differences between $F_{1}$ reciprocal crosses were tested in order to check maternal and/or X-linked effects. Since reciprocal crosses did not differ, the comparisons between mid-parent $F_{1}$ and $F_{2}$ progenies were performed on averaged means (table VII). The results show that the differences between magnetic field and control lines have a genetic basis. The genes involved seem to act additively, since no differences between the means were detected in the following generations. Table VII also reports variance estimates. The variance contains both genetic and environmental components, but the differences among parental lines and hybrid generations should be largely genetic. The test on variance shows a constancy in $F_{1}$ variances and a high level of segregation variance in the $F_{2}$ generation.

The results concerning fitness components are given in table VIII. The differences between reciprocal crosses were always not significant and mean values and standard errors of the 2 lines were averaged. They refer to developmental time and productivity recorded in progenies from 30 pairs ( 35 for $\mathrm{F}_{2}$ generation). The results show that $F_{1}$ hybrids develop carlier and produce many more $F_{2}$ progeny than the 
Table VII. (A) Mean values ( $\pm \mathrm{SE}$ ) and mean squares of control and treated lines (Pc and $\mathrm{Pt}$ ) of the $\mathrm{C}$ stock and of $\mathrm{F}_{1}$ and $\mathrm{F}_{2}$ hybrids. The crosses were made after 9 generations of treatment. (B) Differences between mean values of control and treated lines and between $\mathrm{F}_{1}$ and $\mathrm{F}_{2}$ hybrids. The significance is based on the $t$-test. Variance comparisons between parents and hybrids. The significance is based on the $F$ test. $\mathrm{P}=$ mid-parent.

\begin{tabular}{|c|c|c|c|c|c|}
\hline $\begin{array}{l}\text { (A) } \\
\text { Lines }\end{array}$ & $\mathrm{N}$ & Wing size & & \multicolumn{2}{|c|}{ Mean squares } \\
\hline $\mathrm{Pc}$ & 60 & $53.930 \pm 0.140$ & & \multicolumn{2}{|c|}{0.660} \\
\hline $\mathrm{Pt}$ & 60 & $55.420 \pm 0.110$ & & \multicolumn{2}{|c|}{0.513} \\
\hline $\mathrm{F}_{1}$ & 60 & $54.940 \pm 0.140$ & & \multicolumn{2}{|c|}{0.533} \\
\hline $\mathrm{F}_{2}$ & 60 & $55.080 \pm 0.160$ & & \multicolumn{2}{|c|}{1.506} \\
\hline \multicolumn{6}{|l|}{ (B) } \\
\hline & $d f$ & Differences & Ratio & $d f / d f$ & F-test \\
\hline $\mathrm{Pt}-\mathrm{Pc}$ & 118 & $1.490^{*}$ & $\mathrm{Pc} / \mathrm{Pt}$ & $50 / 50$ & 1.28 \\
\hline $\mathrm{F}_{1}-\mathrm{P}$ & 118 & 0.265 & $\mathrm{P} / \mathrm{F}_{1}$ & $50 / 50$ & 1.15 \\
\hline $\mathrm{F}_{1}-\mathrm{F}_{2}$ & 118 & -0.140 & $\mathrm{~F}_{2} / \mathrm{F}_{1}$ & $50 / 50$ & $2.83^{*}$ \\
\hline $\mathrm{F}_{2}-\mathrm{P}$ & 118 & 0.405 & $\mathrm{~F}_{2} / \mathrm{P}$ & $50 / 50$ & $2.46^{*}$ \\
\hline
\end{tabular}

* Significance at the $1 \%$ level.

Table VIII. (A) Mean values ( $\pm \mathrm{SE}$ ) of developmental time and productivity of control and treated lines $\left(\mathrm{Pc}\right.$ and $\mathrm{Pt}$ ) of the $\mathrm{C}$ stock and of $\mathrm{F}_{1}$ and $\mathrm{F}_{2}$ hybrids. The crosses were made after 9 generations of treatment. (B) Differences between treated and control lines and between $F_{1}$ and $F_{2}$ hybrids. The significance is based on the $t$-test. $\mathrm{P}=$ mid-parent.

\begin{tabular}{|c|c|c|c|}
\hline & & Developmental time & Productivity \\
\hline \multicolumn{4}{|l|}{ (A) } \\
\hline Lines & $\mathrm{N}$ & & \\
\hline $\mathrm{Pc}$ & 30 & $9.298 \pm 0.063$ & $46.370 \pm 4.031$ \\
\hline $\mathrm{Pt}$ & 30 & $9.418 \pm 0.046$ & $40.711 \pm 4.220$ \\
\hline $\mathrm{F}_{1}$ & 30 & $9.079 \pm 0.063$ & $79.593 \pm 4.530$ \\
\hline $\mathrm{F}_{2}$ & 35 & $9.417 \pm 0.050$ & $45.191 \pm 3.524$ \\
\hline \multicolumn{4}{|l|}{ (B) } \\
\hline Comp & $d f$ & & \\
\hline $\mathrm{Pt}-\mathrm{Pc}$ & 58 & +0.120 & -5.659 \\
\hline$F_{1}-P$ & 58 & $-0.279^{*}$ & $36.053^{* *}$ \\
\hline $\mathrm{F}_{1}-\mathrm{F}_{2}$ & 63 & $-0.338^{* *}$ & $34.402^{* *}$ \\
\hline $\mathrm{F}_{2}-\mathrm{P}$ & 63 & +0.059 & 1.651 \\
\hline
\end{tabular}

${ }^{*}$ Significance at the $1 \%$ level; ${ }^{* *}$ Significance at the $0.5 \%$ level. 
parents. This shows evidence of hetcrosis in the crosses between magnetic field and control lines.

\section{Cell number and cell area}

The developmental reasons for the size differences observed between the 2 lines were investigated by studying cell size and number variation. Both parameters seem to be under genetic control (Robertson, 1959a; Cavicchi et al, 1985).

The relationships between wing size, cell size and number are given in table IX for magnetic field and control lines. In the control, both cell area and, more strongly, cell number are positively correlated with wing size, but they are not related to each other. In the magnetic field line, only cell number is positively correlated with wing area, while cell area and number show an inverse correlation. It seems, therefore, that both cell parameters are involved in wing surface determination in the control line, but only cell number is involved in the magnetic field line. So the size differences between magnetic field and control line depend either on cell size or number, but cell area seems to compensate for cell number variations.

Table IX. Correlation coefficients between cell area, cell number and wing area in the control and treated $\mathrm{C}$ stock. The measurements were taken after 9 generations of treatment $(d f=58)$.

\begin{tabular}{lccc} 
& Cell area-cell No & Cell area-wing area & Cel No-wing area \\
\hline Control & -0.112 & $0.462^{*}$ & $0.829^{* *}$ \\
Treated & $-0.508^{*}$ & 0.120 & $0.794^{* *}$ \\
\hline
\end{tabular}

${ }^{*}$ Significance at the $5 \%$ level; ${ }^{* *}$ Significance at the $1 \%$ level.

Similar behaviour of cell number and wing area is also evident in the genetic analysis reported in table $\mathrm{X}$. The results are less clear-cut than those obtained on wing length, owing to the decrease in cell number and wing size means in the $\mathrm{F}_{2}$ and the non significant increase of $\mathrm{F}_{2}$ variances compared with those of midparent. The $F_{1}$ crosses exhibit a significant and inexplicable decrease in wing size and cell number variances when compared with the parental ones and a significant increase in $\mathrm{F}_{2}$ variances compared with the $\mathrm{F}_{1}$ ones. On the contrary, both means and variances of cell area remain constant during cross generations.

On the whole, the results indicate segregation of genes controlling cell number and wing area but not of genes which regulate cell size.

These results confirm that cell area and number are 2 independent parameters, genetically correlated in determining wing size even though cell number rather than cell area is the parameter most affected by magnetic field.

\section{Mutagenesis test}

Table XI summarizes the numbers of sex-linked recessive lethal genes obtained in the tests on 2 treated and untreated lines. These values are the sum of the estimates 
Table X. (A) Mean values ( \pm SE) of cell area, cell number and wing area of control and treated lines $\left(\mathrm{Pc}\right.$ and $\mathrm{Pt}$ ) of the $\mathrm{C}$ stock and of $\mathrm{F}_{1}$ and $\mathrm{F}_{2}$ hybrids. The crosses were made after 9 generations of treatment. $\mathrm{P}=$ mid-parent. (B) Differences between mean values of control and treated lines and between $F_{1}$ and $F_{2}$ hybrids. Significance is based on the $t$-test. (C) Variance ratio between parents and hybrids. Significance is based on the $F$-test.

\begin{tabular}{lrccc}
\hline & \multicolumn{1}{c}{ Cell area } & Cell No & Wing area \\
\hline (A) & & & & \\
Lines & $\mathrm{N}$ & & & \\
$\mathrm{Pc}$ & 45 & $0.4112 \pm 0.0074$ & $8.0919 \pm 0.017$ & $8.5032 \pm 0.0131$ \\
$\mathrm{Pt}$ & 45 & $0.4611 \pm 0.0060$ & $8.1382 \pm 0.0990$ & $8.5993 \pm 0.0086$ \\
$\mathrm{~F}_{1}$ & 32 & $0.4402 \pm 0.0069$ & $8.0841 \pm 0.0134$ & $8.5243 \pm 0.0091$ \\
$\mathrm{~F}_{2}$ & 48 & $0.4507 \pm 0.0053$ & $8.0630 \pm 0.0099$ & $8.5138 \pm 0.0100$ \\
$(\mathrm{~B})$ & & & & \\
$\mathrm{Pt}_{-} \mathrm{Pc}$ & $8 f$ & & & \\
$\mathrm{~F}_{1}-\mathrm{P}$ & 79 & $0.0498^{* * *}$ & $0.0463^{* *}$ & $0.0961^{* * *}$ \\
$\mathrm{~F}_{1}-\mathrm{F}_{2}$ & 88 & -0.0105 & -0.0309 & -0.0289 \\
$\mathrm{~F}_{2}-\mathrm{P}$ & 97 & 0.0146 & 0.0211 & 0.0105 \\
$(\mathrm{C})$ & & & $-0.0520^{* *}$ & $-0.0374^{*}$ \\
$\mathrm{P} / \mathrm{F}_{1}$ & $40 / 32$ & 1.268 & & \\
$\mathrm{~F}_{2} / \mathrm{F}_{1}$ & $48 / 32$ & $<1$ & $1.485^{*}$ & $1.927^{* *}$ \\
$\mathrm{~F}_{2} / \mathrm{P}$ & $48 / 40$ & $<1$ & $1.529^{*}$ & $2.046^{* *}$ \\
\hline
\end{tabular}

${ }^{*}$ Significance at the $10 \%$ level ${ }^{* *}$ Significance at the $5 \%$ level ${ }^{* * *}$ Significance at the $1 \%$ level.

Table XI. X-linked lethality test in control and treated lines of 2 stocks (C and R) after 1 generation of exposure. $N$ is the number of $\mathrm{X}$-chromosomes analyzed.

\begin{tabular}{|c|c|c|c|c|}
\hline Stocks & & $\mathrm{N}$ & No of lethals & Lethals (\%) \\
\hline $\mathrm{C}$ & $\left\{\begin{array}{l}\text { Control } \\
\text { Treated }\end{array}\right.$ & $\begin{array}{r}885 \\
1345\end{array}$ & $\begin{array}{r}2 \\
30\end{array}$ & $\begin{array}{l}0.22 \\
2.23\end{array}$ \\
\hline $\mathrm{R}$ & $\left\{\begin{array}{l}\text { Control } \\
\text { Treated }\end{array}\right.$ & $\begin{array}{r}814 \\
1153\end{array}$ & 12 & $\begin{array}{l}0.12 \\
1.04\end{array}$ \\
\hline
\end{tabular}

obtained in 4 successive experiments and refer to a total of $2230 \mathrm{X}$-chromosomes (treated + control) for stock $\mathrm{C}$ and $1967 \mathrm{X}$-chromosomes for stock $\mathrm{R}$.

The percentages of lethality obtained in the control lines are within the range of values found when similar tests were performed on wild populations of Drosophila (Wagner and Mitchell, 1964). Much higher (10-fold) lethality estimates were found in the same lines when they were exposed to the magnetic field for the whole development cycle. The percentages of lethality obtained in the treated lines were 
similar to the results of tests made on wild populations of Drosophila treated with X-rays at an intensity of 1000 roentgen (Spencer and Stern, 1948; Uphoff and Stern, 1949).

\section{DISCUSSION}

Mutagenicity tests performed on several systems (Mittler, 1971; Kale and Baum, 1979, 1982; Mileva et al, 1985; Juutilainen and Liimatainen, 1986) have failed to demonstrate any mutagenic effect of strong magnetic fields for short periods, but a statistically significant increase of chromosomal aberrations has been observed in human lymphocytes in an experiment of exposure to pulsed electro-magnetic fields of amplitudes ranging from 10-40 Gauss (Garcia-Sagredo and Monteagudo, 1991).

Morphological modifications triggered by biomagnetism were reported by Brewer (1979). A significant increase in body size in comparison with both treated and control lines and in the size of the progeny examined in 3 subsequent generations was found in Lebistes reticulatus subjected to a continuous treatment of a 500 Gauss homogeneous magnetic field. However, these effects are not permanent: in 2 generations after removal from the magnetic field, brood size was nearly normal for a laboratory stock.

Our results offer evidence that chronic exposure to a magnetic field 10-12 times greater than the earth's increases body size in populations of Drosophila melanogaster and this increase persists even when flies are returned to control environmental conditions after a few generations of exposure.

This variation is non-random since the change in always in the plus direction in all the treated lines. Similar results are found with colchicine treatment, in different lines of Lolium perenne, where variations of agronomic quantitative characters, stable over many years and transmitted through a selfed-seed generation, are always in the plus direction (Francis and Jones, 1989). Generally speaking, laboratory populations of Drosophila melanogaster subjected to directional artificial selection pressure for body size resume the control size if selection is relaxed after a few generations (Robertson, 1957; Tantawy and El-Helw, 1966). In our experiment, the size increase depends, therefore, on genes that are selected early on and/or induced after very few generations of exposure as also revealed by the genetic test performed after only 9 generations of exposure.

Moreover, it is known that in Drosophila the environmental effect on body size (eg temperature) is mainly focussed on the genes which control cell size (Robertson, $1959 \mathrm{~b}$; Cavicchi et al, 1985). On the other hand, our results emphasize that the increase in body size is mainly associated with cell number, suggesting that the magnetic field effect on size depends on genes which control cell proliferation.

The significantly longer duration of the larval period exhibited by flies maintained in a higher magnetic field could be correlated with the magnetic field-induced increase in body size since there is a high correlation between length of development and body size under favourable conditions (Robertson, 1957).

Although body size is known to be controlled by several genes located on different chromosomes in Drosophila melanogaster (Kearsey and Kojima, 1967; Cavicchi et al, 1989), our findings do not indicate which genes are mainly involved in determining the size differences observed between treated and control populations. 
The segregational pattern of the crosses does not establish whether one or several genes are involved. More specific genetic analyses are planned in this regard. In any case, wing size variations noted in the gencrations bred in the magnetic field are very similar to those obtained following artificial selection. This suggests that the magnetic field affects several genes. The evolution of the fitness components, fecundity and viability, in the generations of lines subjected to continuous treatment gives some evidence of the underlying genetic mechanism involved. The sudden drop in fitness values in a population subjected to any treatment may occur for 2 genetic reasons: 1) the treatment induces lethal or sublethal mutations; 2) the treatment constitutes environmental conditions unfavourable to the population which undergoes an increase in selection pressure.

In the first instance, the mutagenic effect is expected to persist through the treated generations, unless only some genes are the treatment targets. In the second case, it is plausible to assume that if the conditions are compatible with continuing vital functions, the population will adapt to the new conditions with a consequent increase in fitness. In our case, the lower percentage of emerged flies in relation to egg number found in the line bred in the magnetic field is a clear indication of embryonic lethality or mortality at some larval stage. This event could reflect the fact that the magnetic field acts as a physical mutagenic agent at some stage during embryonic or larval development. The mutagenicity test carried out in this study confirms that one generation of exposure induces lethal mutations 10 -fold greater than the natural rate observed in the control group. The response in terms of increased size would therefore appear to be due to mutations of genes involved in cell proliferation.

In this connection, it is interesting to note the size variations obtained in isogenic lines following treatment. As each isogenic line presents each of the 3 major chromosomes duplicated and identical both within an individual and in all individuals, its genetic variability is zero. No form of selection can act on a population without genetic variability. Hence, the same size differences observed following treatment in the isogenic lines as in the outbred stocks can only be mutational.

However, phenotypic variation of our lines subjected to magnetic field treatment is not random, since the change is always in the plus direction. On this basis, the different hypotheses could not be mutually exclusive. In fact, some mutations should be deleterious and can decrease fitness but a lucky few should be beneficial and also help the adaptation of the population to the new environmental conditions. Furthermore, some organisms could withstand a high mutation rate and still be able to competc. If this happens we must think that there is genetic variation in the rate of mutation or that individuals whith different rates differ in fitness.

Some results of the dose-response relation for X-ray induced mutations in Drosophila melanogaster confirmed a genetic response to chronic radiation dosage that lowered the rate of mutation. Although X-irradiation causes an initial reduction of fertility, after several generations an adaptation of irradiated populations was shown. At least 2 mechanisms are suggested to explain adaptation: an increased oviposition rate and/or a decreased radiosensitivity (Nothel, 1970, 1987).

In our case the second mechanism seems at work, since oviposition follows the same trend of viability. 
The evolution of fitness characters generations could reflect the presence of clusters of target genes, but this can be verified directly only by a mutagenicity test after many generations of treatment.

Though further research will answer all the questions raised in this work, we can conclude at present that chronic exposure to a permanent static magnetic field has mutagenic effects on living organisms. The low magnetic field intensity adopted in this experiment implies that geomagnetic field variations in time and space may be involved in evolutionary phenomena.

\section{ACKNOWLEDGMENTS}

We thank R Barale and G Luigi Dalla Pozza for valuable suggestions. This research was supported by a grant from the Ministero della Università e Ricerca Scientifica, Rome, Italy.

\section{REFERENCES}

Anderstam B, Hamnerius Y, Hussain S, Ehrenberg L (1983) Studies of possible genetic effects in bacteria of high frequency electromagnetic fields. Hereditas 98 , $1-32$

Bloxham J, Gubbins D (1985) The secular variation of earth's magnetic field. Nature $317,777-781$

Brewer HB (1979) Some preliminary studies of the effects of a static magnetic field on the life cycle of the Lebistes reticulatus (guppy). Biophys $J 28,305-314$

Cairns J, Overbaugh J, Stephan M (1988) The origin of mutants. Nature 335, 142145

Cavicchi S, Guerra D, Giorgi G, Pezzoli C (1985) Temperature-related divergence in experimental populations of Drosophila melanogaster. I. Genetic and developmental basis of wing size and shape variation. Genetics 109, 665-689

Cavicchi S, Guerra D, Giorgi G, Pezzoli C (1989) Temperature-related divergence in experimental populations of Drosophila melanogaster. II. Correlation between fitness and body dimensions. I Evol Biol 2, 235-251

Cullis CA (1986) Phenotypic consequences of environmentally induced changes in plant DNA. Trends Genet 2, 307-309

Cullis CA (1990) DNA rearrangements in response to environmental stress. In: Advances in Genetics (Scandalios JG, ed) Academic Press, San Diego, CA, vol 28, 73-97

Delcour J, Lints FA (1966) Environmental and genetic variations of wing size, cell size and cell division rate, in Drosophila melanogaster. Genetica 37, 543-556

Durrant A (1971) Reversion of induced changes in amount of nuclear DNA in Linum. Heredity 27, 431-439

Falconer DS (1970) Introduction to Quantitative Genetics. Oliver and Boyd, Edinburgh

Francis A, Jones RN (1989) Heritable nature of colchicine-induced variation in diploid Lolium perenne. Heredity 62, 407-410 
Frazier ME, Andrews TK, Thompson B (1979) In vitro evaluation of biomagnetic effects. In: Biological Effects of Extremely Low Frequency Electromagnetic Fields (Phillips RD, Gillis MF, eds) US Dept Energy

Garcia-Sagredo JM, Monteagudo JL (1991) Effect of low-level pulsed electromagnetic fields on human chromosomes in vitro. Analysis of chromosomal aberrations. Hereditas $115,9-11$

Goodman EM (1976) Effects of extremely low frequency electromagnetic fields on Physarum polycephalum. Radiat Res 66, 531-540

Goodman EM, Greenebaum B, Marron MT (1979) Bioeffects of low frequency electromagnetic fields. Variation with intensity, waveform and individual or combined electric and magnetic fields. Radiat Res 78, 485-501

Goodman R, Bassett CA, Henderson A (1983) Pulsing electromagnetic fields induce cellular transcription. Science 220, 1283-1285

Goodman R. Krim A, Henderson A, Weisbrot DR (1987) Gene activation in Drosophila salivary gland cells exposed to low frequency non-ionizing radiation. Genetics 116, 50

Juutilainen J, Liimatainen A (1986) Mutation frequency in Salmonella exposed to weak 100-Hz magnetic fields. Hereditas 104, 145-147

Kale PG, Baum JW (1979) Genetic effects of strong magnetic fields in Drosophila melanogaster. I. Homogeneous fields ranging from 13000 to 37000 Gauss. Environ Mutagen 1, 371-374

Kale PG, Baum JW (1982) Genetic effects of strong magnetic fields in Drosophila melanogaster. III. Combined treatment with homogeneous fields and gaseous DBCP. Mutat Res 105, 79-83

Kearsey MJ, Kojima KI (1967) The genetic architecture of body weight and egg hatchability in Drosophila melanogaster. Genetics 56, 23-37

Levengood WC (1966) Cytogenetic variations induced with a magnetic probc. Nature 5027, 1009-1013

Levengood WC (1967) Morphogenesis as influenced by locally administered magnetic fields. Biophys $J$ 7, 297-307

Liboff AR, Williams T Jr, Strong DM, Wistar R Jr (1984) Time-varying magnetic fields: effect on DNA synthesis. Science 223, 818-820

Lindsley DL, Greel EH (1968) Genetic Variations of Drosophila Melanogaster. Carnegie Inst Wash Publ

Mahlum DD, Sikov MR, Decker JR (1979) Dominant lethal studies in mice exposed to direct current magnetic field. In: Biological Effects of Extremely Low Frequency Electromagnetic Fields (Phillips RD and Gillis MF, eds) US Dept Energy

Malinin GI, Gregory WD, Morelli L, Sharma VK, Houck JC (1976) Evidence of morphological and physiological transformation of mammalian cells by strong magnetic fields. Science 194, 844-846

Marron MT, Goodman EM, Greenebaum B (1975) Mitotic delay in the slime mould Physarum polycephalum induced by low intensity 60 - and $75-\mathrm{Hz}$ electromagnetic fields. Nature 254, 66-67

Mileva M, Bulanova M, Ivanov B (1985) Permanent magnetic ficld exposure in vivo and in vitro to the genetic structures of somatic cells. Mutat Res 147, 309

Mittler S (1971) Failure of magnetism to influence production of X-ray induced sex-linked recessive lethals. Mutat Res 13, 287-288 
Mulay IL, Mulay LN (1961) Magnetic effect on Drosophila melanogaster. Nature 190 (4780), 1019

Mulay IL, Mulay LN (1964) Effect on Drosophila melanogaster and S-37 tumor cells; postulates for magnetic field interactions. In: Biological Effects of Magnetic Fields (Barnothy MF, ed) Plenum Press, NY, 146-169

Nothel H (1970) Investigations on radiosensitive and radioresistant populations of Drosophila melanogaster. I. Decreased radiosensitivity in stage- 7 oocytes of the irradiated populations RO I. Mutat Res 10, 463-474

Nothel H (1987) Adaptation of Drosophila melanogaster populations to high mutation pressure. Evolutionary adjustment of mutation rates. Proc Natl Acad Sci USA 84, 1045-1049

Ramon C, Ayaz M, Sreeter DD (1981) Inhibition of growth rate of Escherichia coli induced by extremely low-frequency weak magnetic ficlds. Bioelectromagnetics 2, 285-289

Robertson FW (1955) Selection response and the properties of genetic variation. In: Population Genetics: The Nature and Causes of Genetic Variability. Cold Spring Harbor, NY, 166-177

Robertson FW (1957) Studies in quantitative inheritance. XI. Genetic and environmental correlation between body size and egg production in Drosophila melanogaster. J Genet 55, 428-443

Robertson FW (1959a) Studies in quantitative inheritance. XII. Cell size and number in relation to genetic and environmental variation to body size in Drosophila. Genetics 44, 869-895

Robertson FW (1959b) Studies in quantitative inheritance. XIII. Interrelation between genetic bchavior and development in the cellular constitution of the Drosophila wing. Genetics 44, 1113-1130

Spencer WP, Stern C (1948) Experiments to test the validity of the linear Rdose/mutation frequency relation in Drosophila at low dosage. Genetics 33, 43-74

Tantawy AO, El-Helw MR (1966) Studies on natural populations of Drosophila. V. Correlated response to selection in Drosophila melanogaster. Genetics 53, 97-110 Tegenkamp TR (1969) Mutagenic effects of magnetic fields on Drosophila melanogaster. In: Biological Effects of Magnetic Fields (Barnothy MF, ed) Plenum Press, NY, 189-206

Uphoff DE, Stern C (1949) The genetic effects of low intensity irradiation. Science $109,609-610$

Wagner RP, Mitchell HK (1964) Genetics and Metabolism. John Wiley, New York Watkins ND, Goodell HG (1967) Geomagnetic polarity change and faunal extinction in the southern ocean. Science 156, 1083-1086

Weisbrot DR, Goodman R, Henderson A (1988) Identification by transcription autoradiography of specific chromosome bands in Drosophila melanogaster, responding to low frequency electromagnetic fields. Genome 30 suppl 1, 304 